\title{
Estratégia de inovar? Uma resenha da literatura recente e novas evidências para os diversos setores da economia brasileira a partir da PINTEC
}

\author{
Innovation as a Strategy? A Review of Recent Literature and New PINTEC's \\ Evidences for the Several Sectors of the Brazilian Economy
}

Raphael Douglas dos Anjos Almeida, Robson Antonio Grassi e Edson Zambon Monte**

\begin{abstract}
Resumo: O presente artigo tem como objetivo verificar a assertividade da teoria econômica Neoschumpeteriana ao analisar empiricamente os impactos que o tamanho da firma e o esforço para inovar exercem sobre a receita líquida de vendas (RLV). Utilizando os dados da PINTEC para os anos 2008, 2011 e 2014, e o método de Mínimos Quadrados Ordinários, foram elaboradas seis análises cross-section, duas para cada ano. Os modelos do Tipo 1 verificam o impacto do tamanho da firma (em termos de pessoas ocupadas) e dos gastos totais com inovação sobre a RLV, e os modelos do Tipo 2 analisam os impactos do tamanho da firma e dos gastos com atividades internas de P\&D sobre a RLV. Ao fim, os modelos propostos ratificaram a teoria econômica e a produção literária mais recente sobre o tema, pois constatou-se que todas as variáveis selecionadas impactaram positivamente a RLV ao longo dos anos estudados. Além disso, a pesquisa contribuiu para a ampliação da literatura acerca da inovação ao utilizar os dados mais recentes da PINTEC e demonstrar o impacto específico das atividades internas de P\&D sobre a RLV.
\end{abstract}

Palavras-chave: Inovação. Teoria Neoschumpeteriana. PINTEC. Mínimos Quadrados Ordinários

\begin{abstract}
This paper aims to verify the assertiveness of Neoschumpeterian economic theory by empirically analyzing the impacts that the firm size and the effort to innovate exert on net sales revenue (RLV). Using the PINTEC data for 2008, 2011 and 2014, and the Ordinary Least Squares method, six cross section analysis were performed, two for

\footnotetext{
* Submissão: 24/09/2019. Aprovação: 02/03/2020. DOI: http://dx.doi.org/10.5380/re.v41i76.69334. O presente trabalho foi realizado com apoio da Coordenação de Aperfeiçoamento de Pessoal de Nível Superior - Brasil (CAPES) - Código de Financiamento 001.

** Respectivamente: (1) Mestre em economia pelo Programa de Pós-Graduação em Economia da Universidade Federal do Espírito Santo (PPGEco/UFES).E-mail: rda.raphael@gmail.com. ORCID: 00000002-4279-9020. (2) Professor do Departamento de Economia e Programa de Pós-Graduação em Economia da Universidade Federal do Espírito Santo (PPGEco/UFES). E-mail: ragrassi@uol.com.br. Orcid: 00000003-3735-3427. (3) Professor do Departamento de Economia, do Programa de Pós-Graduação em Economia (PPGEco) e do Grupo de Pesquisa em Econometria (GPE) da Universidade Federal do Espírito Santo (UFES).E-mail: edsonzambon@yahoo.com.br. ORCID: 0000-0002-6878-5428.
} 
each year. Type 1 models look at the impact of the firm size (in terms of employed persons) and total innovation expenditures on RLV and Type 2 models analyze the impact of the firm size and internal R\&D activity spending on RLV. Finally, the models proposed ratified the economic theory and the most recent literature on the theme, since all the selected variables positively impacted RLV over the studied years. In addition, the research contributed to the expansion of the literature on innovation by using the latest PINTEC data and demonstrating the specific impact of internal $R \& D$ activities on the RLV.

Keywords: Innovation. Neoschumpeterian Theory. PINTEC. Ordinary Least Squares

JEL Code: C31; O14; O32 


\section{Introdução}

O objetivo de uma empresa é em primeiro lugar sobreviver e em segundo lugar crescer. Para alcançar ambos os objetivos, a firma busca estratégias que, ao mesmo tempo, aumentem seus lucros e evitem algum prejuízo à sua posição futura (ROBINSON, 1988). Nesse sentido, a literatura demonstra que a inovação funciona como uma dessas estratégias tanto para ampliar as receitas das empresas quanto para impulsionar o desenvolvimento econômico e a concorrência dentro dos mais variados setores do mercado.

Além dos fatores supracitados, a progressiva abertura econômica do mercado internacional, aprofundada no Brasil a partir de meados da década de 1990, exerce pressão considerável sobre a necessidade de inovar. A concorrência, agora, não acontece apenas dentro do país; ela é elevada a níveis internacionais de produtividade (SILVA; SANTANA, 2015). O cenário, incerto e dinâmico, mostra que é decisivo para os níveis de rentabilidade da firma não somente inovar, como também manter e ampliar a capacidade inovativa.

Vale ressaltar que empresas de maior porte apresentam vantagem nessa concorrência. Os custos para manter um setor ativo de Pesquisa e Desenvolvimento (P\&D), além dos dispêndios com aquisições externas, treinamento especializado e comercialização de inovações, podem ser proibitivos em empresas de menor porte. Os gastos com bens e serviços utilizados pelo setor de P\&D das firmas podem ser caracterizados como gastos irrecuperáveis (sunk costs), funcionando como barreiras à entrada em diversos setores da economia (HERSCOVICI, 2010).

Dessa forma, é objetivo do presente artigo verificar empiricamente a assertividade da teoria econômica Neoschumpeteriana ao calcular a influência que o tamanho da empresa (pessoal ocupado) e o esforço de inovação (gastos com atividades inovativas) exercem sobre a sua performance financeira (receita líquida de vendas). A metodologia baseia-se nos artigos de Becker e Dal Bosco (2011) e de Silva e Santana (2015), trazendo avanços na análise econométrica em relação aos resultados anteriores. Dentre estes avanços, pode-se citar:

1) A utilização dos dados publicados em 2016 (versão mais recente) da Pesquisa de Inovação Tecnológica (PINTEC) realizada pelo Instituto Brasileiro de Geografia e Estatística (IBGE); 
2) A inclusão de mais setores da economia brasileira, a saber, além da Indústria de Transformação, também são analisados a Indústria Extrativa e o setor de Serviços Ligados à Tecnologia ${ }^{1}$. Isso permite a construção de uma visão mais geral do comportamento do mercado brasileiro; e

3) A análise do "esforço de inovação" separada em duas etapas²:

a. Uma investigação do impacto total dos dispêndios com atividades inovativas sobre a receita líquida de vendas; e

b. Uma verificação particular da influência dos gastos com atividades internas de P\&D sobre a receita líquida de vendas.

Dessa forma, será possível a construção de uma análise histórica da evolução do tamanho das empresas e do esforço de inovação e o seu impacto sobre a performance financeira das firmas de vários setores em três anos, 2008, 2011 e 2014.

As estimativas foram realizadas por meio do Método de Mínimos Quadrados Ordinários (MQO), sendo que as regressões foram estimadas para cada ano (dados cross-section para cada ano): 2008, 2011 e 2014. Utilizou-se as seguintes variáveis: Receita Líquida de Vendas (RLV), quantidade de pessoas nos setores contemplados, dispêndio total com atividades inovativas e gastos com atividades internas de $\mathrm{P} \& \mathrm{D}$ ao final de cada ano.

Assim como Becker e Dal Bosco (2011) e Silva e Santana (2015), chegou-se à conclusão de que o tamanho da empresa e os gastos totais com atividade inovativa exercem um impacto positivo sobre a RLV, sendo o segundo fator ainda mais impactante que o primeiro. Além disso, como contribuição original, verificou-se que a variável de gastos com atividades internas de $\mathrm{P} \& \mathrm{D}$ também exerce uma influência significativa sobre a RLV, demonstrando a importância desse tipo de investimento dentro dos componentes dos gastos totais com inovação.

Para cumprir seus objetivos, além desta breve introdução, o trabalho é composto por mais quatro seções. A segunda seção aborda a literatura teórica e empírica acerca de tópicos sobre a economia da inovação. A terceira seção descreve

\footnotetext{
${ }^{1}$ A Indústria de Transformação foi o único setor contemplado por Becker e Dal Bosco (2011) e Silva e Santana (2015). Os setores utilizados neste trabalho estão descritos no Apêndice A e os valores relativos às variáveis para todos os anos podem ser vistos diretamente no site do IBGE: http://www.ibge.gov.br/estatisticasnovoportal/multidominio/ciencia-tecnologia-e-inovacao/9141-pesquisa-de-inovacao.

${ }^{2}$ Em Becker e Dal Bosco (2011) e Silva e Santana (2015), a análise cross-section foi feita contemplando somente a variável do Dispêndio Total com Atividade Inovativa.
} 
os dados e o modelo utilizados na pesquisa. A quarta seção discute os resultados obtidos. E, por fim, são tecidas algumas conclusões acerca da pesquisa realizada.

\section{Referencial teórico e empírico: o Paradigma Estrutura-Conduta- Desempenho e a literatura Neoschumpeteriana}

Esta seção aborda parte da literatura econômica que trata sobre inovação, em particular o Paradigma Estrutura-Conduta-Desempenho (ECD) da microeconomia de Organização Industrial e a teoria evolucionária da firma, da escola de pensamento Neoschumpeteriana. Além dessas duas abordagens, também serão apresentados alguns estudos empíricos acerca da temática.

\subsection{O Paradigma Estrutura-Conduta-Desempenho (ECD)}

O Paradigma ECD foi elaborado como uma tentativa de avaliar o desempenho real das empresas, de um setor da economia, em relação ao desempenho esperado em situação de concorrência perfeita. Ou seja, avaliar até que ponto as imperfeições existentes no mercado limitam a capacidade das firmas de atender às demandas da sociedade, além de tentar identificar quais variáveis explicam essa diferença de desempenho (AZEVEDO, 1998; HASENCLEVER; TORRES, 2013).

Para cumprir seu objetivo, o Paradigma ECD estabelece uma relação causal entre a estrutura de mercado em que as firmas estão inseridas, o leque de estratégias (condutas) que as firmas podem adotar e o desempenho econômico da indústria. A estrutura do mercado pode ser definida observando-se o grau de concentração do mercado, a estrutura dos fornecedores e as características dos produtos. Essa estrutura limita e condiciona as estratégias que uma empresa pode adotar para atingir seu objetivo. Por fim, a escolha da estratégia conjuntamente à estrutura de mercado em que a firma opera determinam o seu desempenho (AZEVEDO, 1998).

A Figura 1 mostra um quadro-resumo com as interações do Paradigma ECD. A causalidade principal é designada pelas setas cheias e os efeitos secundários pelas setas pontilhadas. A determinação do desempenho econômico leva em conta as estratégias empresariais (a conduta). Cada firma escolhe a melhor estratégia para atingir seus objetivos observando uma série de fatores presentes na estrutura de mercado, como barreiras à entrada e o grau de concentração, dentre outras características. A estrutura, por sua vez, é definida por condições básicas do 
mercado, como características da demanda, dos produtos e da tecnologia. Os efeitos secundários são mais importantes a longo prazo, dado que é necessário certo tempo para que uma estratégia tenha efeito a ponto de mudar uma estrutura de mercado (HASENCLEVER; TORRES, 2013; SCHERER; ROSS, 1990).

\section{Figura 1 - Interações do Paradigma ECD}

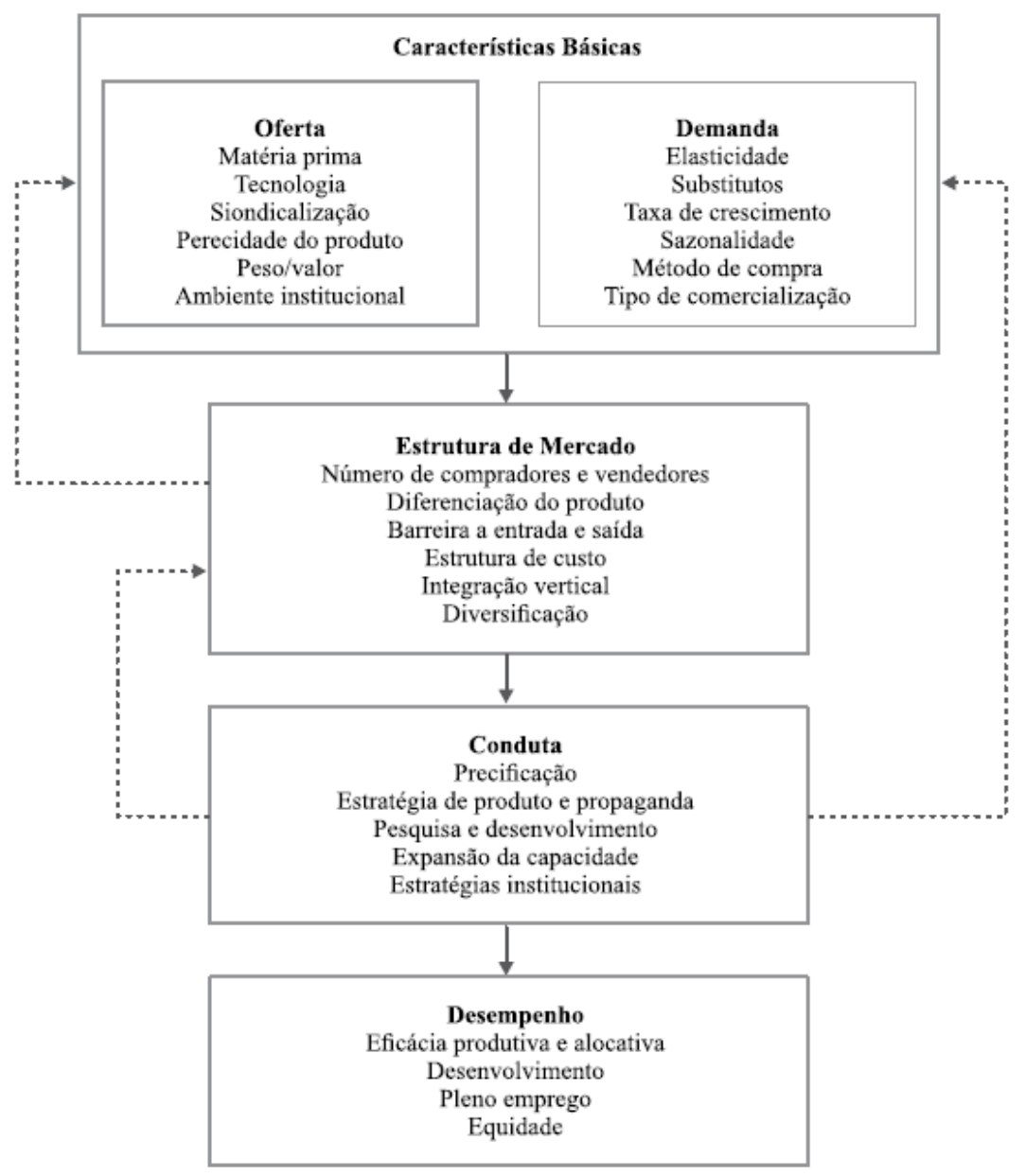

Fonte: Scherer e Ross (1980).

Neste artigo, o desempenho das firmas será analisado em termos do seu faturamento sobre as vendas, e o determinante principal da conduta será a variável de investimentos em inovação, mas sem perder de vista o porte das empresas. Com relação à estrutura de mercado, devido à heterogeneidade dos setores contemplados pela pesquisa, há uma diversidade de estruturas em que as firmas estão inseridas, com vários graus de concentração diferentes e variadas barreiras à entrada. Destarte, uma análise dos efeitos da estrutura sobre a conduta escolhida (inovação) foge ao escopo do trabalho. 
Contudo, de acordo com Kupfer (1992), várias críticas foram tecidas ao paradigma ECD ao longo do tempo:

1) A insuficiência no tratamento das mudanças dos padrões concorrenciais causadas pela influência das modificações de condutas.

2) A incapacidade de lidar com cenários em que existam diferentes níveis de concentração das firmas em uma indústria.

3) A questão da endogeneidade.

Para o autor, a principal falha do paradigma é a crítica sobre a endogeneidade. Ou seja, o Paradigma ECD adota uma visão mecanicista que considera as características básicas e a estrutura como um dado exógeno e, também, o comportamento maximizador da conduta do empresário. Assim, é necessário supor que o empresário tem acesso a informações "quasi-perfeitas" e condições de previsão extremamente acuradas, e irreais, em um mundo incerto. Essas "características estáticas" do paradigma ECD dão margem às críticas da teoria Neoschumpeteriana, que lida com essas incertezas e com a dinâmica das estruturas de mercado.

Lopes (2016) tenta conciliar o paradigma ECD dentro de uma dinâmica Neoschumpeteriana. Para o autor, estrutura, conduta, desempenho e políticas públicas podem funcionar como um sistema em que todos os aspectos se retroalimentam e esse mecanismo de feedback geraria a dinamicidade necessária para combinar as duas correntes de pensamento. O desempenho micro (lucro, preço, eficiência, etc.) alimenta o ambiente evolucionário em que a conduta inovadora modifica as estruturas de mercado contribuindo para um aumento do desempenho.

\subsection{A abordagem Neoschumpeteriana sobre a estratégia inovativa}

A inovação pode ser colocada no centro do desenvolvimento econômico, quer seja como uma combinação diferente de fatores de produção (resultando em novos produtos ou técnicas) ou contribuindo para o surgimento de novos mercados e novas fontes de matéria-prima. $\mathrm{O}$ empreendedor inovador é aquele com visão para implementar essas novas combinações e inserir as inovações no mercado. Quando o empreendedor gera novas combinações, aumentando sua produtividade com relação a processos anteriores, ele pode se apropriar de lucros extraordinários (ou comerciais). Esses lucros geram assimetrias no mercado, criando vantagens competitivas para as empresas. Nota-se, então, que a inovação (e a imitação desta) 
são as responsáveis por trazer vantagens competitivas para as firmas, e, assim, a busca por inovações passa a ser objetivo constante das empresas. Pode-se perceber que a estratégia de inovar é determinante no desempenho das firmas nos mais diferentes mercados (BAUMOL, 1993; SCHUMPETER, 1997).

Essas vantagens competitivas estão diretamente relacionadas ao surgimento da grande empresa. É a firma de grande porte que apresenta maior possibilidade de sucesso no processo inovador, seja pela facilidade com que consegue gerar economias de escala, seja pela ampla estrutura produtiva e disponibilidade de capital físico e financeiro. A partir de uma observação histórica, é possível verificar que a grande empresa é mais bem-sucedida em criar e manter um contínuo investimento em um setor de $\mathrm{P} \& \mathrm{D}$, responsável pela inovação (JENSEN; MENEZES-FILHO; SBRAGIA, 2004; PÓVOA; MONSUETO, 2011).

Contudo, essas empresas não atuam em situação de concorrência perfeita, mas em estruturas de mercado melhores definidas como oligopolistas. Todo agente econômico que comercializa um produto diferenciado se torna um monopolista daquele produto, muitas vezes dispondo de métodos superiores não disponíveis para a concorrência. Nessa estrutura oligopolista, não é possível sustentar a hipótese de que preços acima do concorrencial irão corresponder a uma diminuição da demanda e, por isso, empresas oligopolistas podem se apropriar de lucros extraordinários. Parece razoável supor que, com uma maior disponibilidade de capital, a grande empresa pode apresentar uma maior eficiência técnica em relação à pequena empresa (SCHUMPETER, 1961).

A escola de pensamento Neoschumpeteriana, mais precisamente quando se trata da teoria evolucionária da firma, concebe a indústria como um conjunto heterogêneo de firmas guiadas por rotinas administrativas. As firmas procuram soluções inovadoras (ou imitam soluções) para aumentar o lucro e, como o nome "evolucionária" indica, firmas mais bem-sucedidas nessa atividade inovadora crescem, por vezes aglutinando firmas em posições mais baixas no mercado. Logo, seria natural a formação de uma estrutura oligopolista no mercado. Esse é um processo dinâmico em que a firma interage com outras dentro do ambiente de mercado, criando forças competitivas e a estrutura em que elas competem (NELSON; WINTER, 1982).

Nesse ponto, a teoria Neoschumpeteriana ultrapassa o caráter estático do Paradigma ECD abrindo espaço para a inserção da incerteza e da dinamicidade. A 
busca permanente pela inovação, em um ambiente de seleção, feita pelo mercado mostra um processo dinâmico e incerto, em que o resultado é determinado pelo tempo, e o desempenho da firma pelas suas rotinas, busca e seleção (VIEIRA, 2010).

Vale ressaltar que a presença de oligopólio não é uma oposição a um mercado competitivo. Empresas oligopolistas são fruto de uma conduta inovadora eficiente e bem-sucedida. Para que um ambiente inovador e competitivo exista é necessário que a concorrência (e, por conseguinte, os concorrentes) seja forte. Em outras palavras, devem estar presentes as eficiências técnica, organizacional e produtiva dos concorrentes (POSSAS, 2004).

É essa estrutura de mercado que estabelece o que é o sucesso de uma firma, e essa definição está intimamente ligada à capacidade da firma de sobreviver e crescer (a sobrevivência do mais bem adaptado). A estrutura pode ser considerada como as preferências, as regras do lucro e a relação entre lucro e o movimento de expansão e contração das firmas. É a estrutura que determina: a) o uso das diferentes tecnologias; b) como as tecnologias mudam com o tempo; c) os gastos com P\&D; e d) a relação entre a tecnologia produzida pela firma e o consumidor. Portanto, o ambiente fornece constantemente novos sinais e elementos de que está mudando, e o sucesso da firma depende do seu esforço adaptativo (NELSON; WINTER, 1982).

Assim, percebe-se que a teoria evolucionária da firma enfatiza a inovação como motor para o desenvolvimento das empresas e da economia como um todo. Sobre a dinâmica da inovação atuam fatores como investimentos em P\&D, o nível de aprendizado e a evolução das empresas. A mudança econômica só existe, então, a partir do momento em que produtos e processos são inovadores e a estrutura de mercado seleciona os melhores. Como as firmas trabalham sob vários tipos de incerteza, os meios para sua sobrevivência nesse mercado dinâmico dependem de estratégias inovadoras que geralmente trazem custos elevados, mais uma vez reafirmando a vantagem da grande empresa (CÁRIO, 1995).

Diante do exposto, a inovação precisa de uma base institucional de apoio, ou seja, um processo social que gera aprendizado e abrange fatores como o investimento em P\&D e o desenvolvimento de uma infraestrutura tecnológica. Então, para inovar, as empresas precisam, por um lado, de uma rotina que selecione o que colocar no mercado e, por outro, de uma constante busca de aprendizado. Logo, a inovação poderia ser classificada como uma conduta da empresa diante da 
estrutura de mercado, que inclui investimento em P\&D, infraestrutura tecnológica e estabelecimento de rotinas para criar inovações continuamente (CÁRIO; PEREIRA, 2002).

Destarte, se a inovação tem papel decisivo na concorrência, com o passar do tempo, as empresas precisam ampliar a capacidade inovativa para continuarem competitivas. O caráter contínuo desse processo exige que haja uma rotina que comece com atividades científicas e tecnológicas. Portanto, estratégias de desenvolvimento focam na ampliação dos gastos com P\&D para incrementar o conhecimento e disseminar a inovação. O aumento dos gastos desse setor de P\&D em relação ao capital fixo das empresas mostra a importância crescente da estratégia de domínio tecnológico (LASTRES; CASSIOLATO, 2003).

O presente artigo considera a estrutura de mercado como um dado exógeno e trabalha as hipóteses da influência do tamanho e da conduta inovativa (na forma de gastos totais com inovação e gastos com atividades internas de P\&D) sobre o desempenho das firmas. Essas hipóteses já vêm sendo testadas na literatura pertinente, com os resultados que serão apresentados na seção seguinte.

Em certa medida, considerar a estrutura como exógena aproximaria o trabalho do Paradigma ECD, mas a realização do estudo para vários anos evoca o tratamento da inovação sob o enfoque Neoschumpeteriano. Em primeiro lugar, por tratar a inovação como um dos determinantes centrais para o crescimento das empresas, em termos do seu faturamento (superando o paradigma ECD no qual a inovação pode ser apenas uma conduta dentre várias). Em segundo lugar, analisar a influência dos gastos com P\&D sobre a receita líquida de vendas das empresas em três execuções da PINTEC permite observar não somente o efeito em um dos anos como também um quadro histórico, pois a decisão de investir em atividades inovativas reverbera ao longo do tempo, e o desempenho retroalimenta a conduta.

\subsection{Revisão da literatura empírica}

A relação entre inovação e desempenho das firmas tem sido objeto de extensa análise empírica ao longo dos anos. Algumas conclusões podem ser apresentadas a partir de estudos que tratam como este e outros fatores afetam a rentabilidade das empresas. Sobre a relação entre o porte da empresa e o desempenho, no mercado mais competitivo, as firmas que empreendem primeiro em inovações são as que conseguem obter menores custos e maiores lucros. 
Contudo, quanto mais concentrada a estrutura, firmas com maior poder de mercado podem impor suas políticas de preços e aumentar sua margem de lucro, de forma que a concentração pode afetar os investimentos em P\&D. Portanto, a relação entre o nível de concentração e a lucratividade é um fator a ser levado em consideração (MENDONÇA; LIMA, 2009).

Em outro sentido, Jensen, Menezes-Filho e Sbragia (2004) apontam que o tamanho da firma (em termos de capital físico) e o faturamento bruto são fatores determinantes sobre o investimento em P\&D. Contudo, contradizendo Mendonça e Lima (2009), eles observam que flutuações na lucratividade não exercem efeito determinante sobre o investimento em $P \& D$, já que este último se trata de um investimento de longo prazo.

Apesar da relação direta entre tamanho e desempenho, vale ser destacado que o esforço inovador também tem resultado positivo sobre pequenas e médias empresas. $\mathrm{O}$ esforço para criar e manter um setor de $\mathrm{P} \& \mathrm{D}$, apesar de proporcionalmente maior para pequenas e médias empresas, tem impacto positivo no seu crescimento se adotado como estratégia (MACEDO; ALBUQUERQUE, 1997).

Por meio de uma análise exploratória não-paramétrica da PINTEC, Kannebley Jr., Porto e Pazello (2004) demonstram que dentre as principais características que afetam a probabilidade de uma empresa ser inovadora estão a orientação exportadora e o tamanho (medido em número de empregados). Vale ressaltar que, para os autores, a probabilidade de inovar aumenta mais que proporcionalmente em relação ao aumento do número de empregados.

Através de uma comparação internacional, Viotti, Baessa e Koeller (2005) demonstram que apesar do tamanho da empresa influenciar sobre os gastos totais com atividade inovativa, e as empresas de grande porte serem as maiores responsáveis pela inovação, a concentração de grandes empresas no Brasil é maior do que a média dos países selecionados (União Europeia), e mesmo assim o Brasil inova menos, proporcionalmente, indicando um papel relevante para pequenas e médias empresas. Além disso, é demonstrado no estudo que o maior responsável pela inovação nos setores da economia são as empresas que desenvolvem a inovação internamente, apontando para uma maior relevância dos gastos com atividades internas de $\mathrm{P} \& \mathrm{D}$ dentre todos os gastos com atividade inovativa.

Por fim, os dois estudos em que este artigo se baseou mostram que é válida a ideia de que tamanho e dispêndios com atividades inovativas influenciam 
positivamente o desempenho da indústria de transformação brasileira (BECKER; DAL BOSCO, 2011). E, mais ainda, que esse resultado se repete quando aplicado individualmente a todas as regiões do Brasil ao longo do tempo (SILVA; SANTANA, 2015). Logo, seria importante para a empresa investir em inovações e na sua estrutura produtiva e de capital, para torná-la mais robusta e competitiva nos mercados. O estudo econométrico que começa na seção seguinte tenta contribuir para esse debate com novos resultados e um olhar mais amplo, em relação aos dois artigos anteriores.

Mais especificamente sobre a PINTEC, Tironi e Cruz (2008) partem do pressuposto de que há um fator limitante das políticas de inovação nacionais, que é tratar a inovação como um evento indiferenciado que objetiva somente aumentar a proporção das empresas que inovam. Isso poderia ser evitado ao se levar em conta o grau de novidade da inovação, pois graus de novidade diferentes poderiam indicar estruturas produtivas e de gestão distintas, permitindo o desenho de políticas públicas diferenciadas. Assim, os autores buscam verificar se a PINTEC oferece a possibilidade de levar em conta o grau de novidade na formulação de políticas públicas. $\mathrm{O}$ estudo descritivo dos autores mostra que, conforme o grau de novidade da inovação aumenta, a importância dos ativos intangíveis (investimentos em P\&D, por exemplo) também aumenta, exigindo padrões de investimento e financiamento diferenciados.

Ainda acerca da PINTEC, Cavalcante e De Negri (2011) estabelecem críticas contundentes às pesquisas de inovação, incluindo a PINTEC. Segundo os autores, mesmo que pesquisas de inovação sejam a principal fonte de dados para análise, elas falham metodologicamente, pois focam nos indicadores de esforços e atividades (gastos com P\&D, por exemplo) e falham em construir indicadores de resultados (impactos de políticas de inovação).

Contudo, mesmo com essas limitações, a PINTEC fornece dados que podem ser amplamente utilizados para vários tipos de correlações. As relações entre P\&D e RLV, por exemplo, são utilizadas na literatura para medir a intensidade tecnológica de setores e empresas, a nível nacional e internacional. No Brasil, a utilização da relação "Gastos em atividade inovativa/RLV" mostra um quadro estável ${ }^{3}$, em que os gastos com atividades inovativas representam, em

\footnotetext{
${ }^{3}$ Entre 1998 e 2008.
} 
média, 2,5\% da RLV, com destaque para os gastos com atividades internas de P\&D em relação à $\operatorname{RLV}(0,55 \%)$.

Já uma análise setorial mostra que é o setor de média-alta tecnologia o maior responsável pelo aumento dos gastos em atividade inovativa no país $(0,37 \%$ de uma contribuição total de $0,75 \%$ ), fornecendo uma ferramenta para elaboradores de políticas públicas projetarem cenários mais otimizados para investimentos (CAVALCANTE; DE NEGRI, 2011).

\section{Modelagem econométrica}

No presente artigo, para realizar a análise empírica verificando-se as relações entre tamanho, esforço de inovação e desempenho, foi adotado o método de MQO para modelagem em cross-section referente aos dados dos anos de 2008, 2011 e 2014, presentes na PINTEC elaborada pelo IBGE.

\subsection{Descrição das variáveis}

A PINTEC abrange entidades organizadas juridicamente como empresas, com sede em qualquer parte do território brasileiro, com dez ou mais pessoas ocupadas em situação ativa no Cadastro Central de Empresas do IBGE (PINTEC, 2016). Para a modelagem proposta no artigo, foram selecionadas as empresas que exercem as seguintes atividades principais: a) Indústria Extrativa; b) Indústria de Transformação; e c) Serviços Ligados à Tecnologia. Foram consideradas as seguintes variáveis para todos os setores contemplados:

a. RLV: Receita Líquida de Vendas (R\$ 1.000,00);

b. PO: Quantidade de pessoas ocupadas ao final de cada ano (número de pessoas ocupadas);

c. INOV: Gastos Totais com Atividades Inovativas (R \$ 1.000,00); e

d. PDI: Dispêndios com Atividades Internas de P\&D (R\$ 1.000,00).

A variável dependente (RLV) é responsável por registrar o desempenho do setor. Esse desempenho foi obtido através da Receita Líquida de Vendas de cada setor. A RLV foi escolhida, pois mede a receita bruta de venda e revenda, deduzida de impostos, vendas canceladas e abatimentos, representando, portanto, uma boa aproximação do faturamento das empresas advindo das suas vendas, diretamente afetadas pela implementação de uma inovação de produto ou processo no mercado. 
A variável PO captura o tamanho do setor em termos da população ocupada ao fim de cada ano analisado. Apesar de não captar o tamanho exato de cada firma do setor, o tamanho da indústria como um todo pode ser usado para captar o efeito que o tamanho exerce sobre a RLV (BECKER; DAL BOSCO, 2011). A literatura aponta que a relação entre a variação da população ocupada e a variação da RLV deverá ser positiva.

As variáveis PDI e INOV vão informar o efeito da conduta com foco em atividades inovativas, de cada setor selecionado, sobre o desempenho das firmas. A variável PDI mede o dispêndio com atividades internas de P\&D. Essas atividades compreendem o "trabalho criativo feito de forma sistemática, cujo objetivo é ampliar o conhecimento atual e utilizá-lo para desenvolver novas aplicações, por exemplo, o desenho, construção e testes de protótipo" (PINTEC, 2016). Espera-se também uma relação positiva entre as variações dos gastos com atividades internas de P\&D e da RLV.

A variável INOV representa os gastos totais com atividades inovativas. Essas atividades compreendem ${ }^{4}$ :

a. Atividades internas de P\&D, já explicadas anteriormente;

b. Aquisição externa de $\mathrm{P} \& \mathrm{D}$, ou seja, as mesmas atividades internas, contudo realizadas por outra organização e adquiridas pela firma em questão;

c. Aquisição de software comprado para implementação de produtos e processos e não desenvolvidos pelas atividades internas de $\mathrm{P} \& \mathrm{D}$;

d. Aquisição de máquinas e equipamentos comprados para implementação de inovações;

e. Treinamento orientado ao desenvolvimento de inovações em produtos e processos, podendo incluir aquisição externa de serviço especializado;

f. Despesas de comercialização ligadas ao lançamento de inovações; e

g. Projeto industrial e outras preparações técnicas para a produção, distribuição e efetiva implementação de inovações.

\footnotetext{
${ }^{4}$ A variável INOV pode, em futuros trabalhos, ser dividida para que cada uma das atividades seja analisada em separado. Contudo, nos dados de 2008 publicados pela PINTEC, não constam os dispêndios de cada um dos setores separadamente (à exceção das atividades internas de P\&D) e para os anos de 2011 e 2014 os dados relativos a cada atividade não estão completos, o que impossibilita os cálculos para as amostras desejadas. Então, achamos pertinente, para o propósito do artigo, que os esforços para inovação fossem analisados em conjunto (INOV) e, após isso, para efeitos de comparação, somente o impacto das atividades internas de P\&D (PDI) foi analisado em separado.
} 
A teoria também prevê uma relação positiva entre as variações dos gastos totais com atividades inovativas e a RLV. A Tabela 1 mostra um resumo da construção das variáveis independentes e do sinal esperado dos seus coeficientes:

Tabela 1 - Resumo das variáveis explicativas

\begin{tabular}{llc}
\hline Variável & \multicolumn{1}{c}{ Descrição } & $\begin{array}{c}\text { Sinal esperado } \\
\text { do coeficiente }\end{array}$ \\
\hline PO & $\begin{array}{l}\text { População ocupada até } 31 / 12 \text { dos anos selecionados } \\
\text { (número de pessoas ocupadas) }\end{array}$ & + \\
PDI & $\begin{array}{l}\text { Dispêndio com atividades internas de } \mathrm{P} \& \mathrm{D}(\mathrm{R} \$ 1.000,00) \\
\text { INOV }\end{array}$ & + \\
\hline
\end{tabular}

Fonte: Elaborado pelos autores.

É possível notar que a variável PDI é uma componente da variável INOV. Sendo assim, uma estimação em uma única equação que levasse em conta as duas variáveis tornaria o modelo inconsistente. Assim, serão elaborados dois modelos para cada ano: os modelos do Tipo 1 levarão em conta o tamanho e o gasto total com atividades inovativas, e os modelos do Tipo 2 levarão em conta o tamanho e os dispêndios com atividades internas de P\&D. Essa análise será feita com a finalidade de comparar o impacto do gasto total com atividades inovativas com o impacto dos gastos com atividades internas de P\&D isoladamente.

\subsection{Metodologia econométrica}

A abordagem escolhida para a análise econométrica dos dados baseia-se no método de Mínimos Quadrados Ordinários. Uma forma simples de otimização que estima os parâmetros ao minimizar a soma dos quadrados das diferenças entre o valor estimado e os dados observados (ou seja, os resíduos) (GUJARATI; PORTER, 2011). Para tal análise, considera-se o modelo de regressão linear múltipla abaixo:

$\mathrm{Y}_{\mathrm{i}}=\beta_{0}+\beta_{1} \mathrm{X}_{\mathrm{i} 1}+\beta_{2} \mathrm{X}_{\mathrm{i} 2}+\varepsilon_{\mathrm{i}}$,

com $\varepsilon_{\mathrm{i}} \sim \mathrm{N}\left(0, \sigma^{2}\right)$ para $\mathrm{i}=1,2, \ldots, \mathrm{n}$. A forma matricial do modelo pode ser representada da seguinte maneira:

$$
\mathbf{Y}=\mathbf{X} \boldsymbol{\beta}+\boldsymbol{\varepsilon}
$$


em que $\mathbf{Y}$ é o vetor de variáveis dependentes, $\mathbf{X}$ é a matriz de variáveis independentes adicionada da coluna de constantes que representam o intercepto, $\boldsymbol{\beta}$ é o vetor de parâmetros a ser estimado e $\boldsymbol{\varepsilon}$ representa o vetor de erros estocásticos (um vetor de variáveis aleatórias não observáveis), com $\boldsymbol{\varepsilon} \sim \mathrm{N}\left(\mathbf{0}, \sigma^{2} \mathbf{I}_{\mathbf{n}}\right)$, sendo $\mathbf{I}_{\mathbf{n}}$ a matriz identidade.

O vetor dos parâmetros estimados pelo método de MQO (b) pode ser expresso da seguinte forma:

$$
\mathbf{b}=\left(\mathbf{X}^{\prime} \mathbf{X}\right)^{-1} \mathbf{X}^{\prime} \mathbf{Y}
$$

No presente artigo, a forma funcional escolhida foi a Log-Log devido à forma prática pela qual se pode obter as elasticidades ao regredir os estimadores (GREENE, 2012). Sendo assim, as duas equações a serem regredidas que correspondem aos modelos do tipo 1 (Equação 4) e do tipo 2 (Equação 5) encontram-se na seguinte forma:

$$
\begin{aligned}
& \ln \left(\mathrm{RLV}_{i}\right)=\lambda+\beta_{1} \ln \left(\mathrm{PO}_{i}\right)+\beta_{2} \ln \left(\mathrm{INOV}_{i}\right)+\varepsilon_{\mathrm{i}} ; \\
& \ln \left(\mathrm{RLV}_{i}\right)=\lambda+\beta_{1} \ln \left(\mathrm{PO}_{i}\right)+\beta_{2} \ln \left(\mathrm{PDI}_{i}\right)+\varepsilon_{\mathrm{i}} .
\end{aligned}
$$

Nas equações, $\lambda=\ln \left(\beta_{0}\right)$ é o intercepto do modelo. Cada um dos modelos foi executado para os três anos que o estudo se propõe a verificar (2008, 2011 e 2014), resultando finalmente em seis análises cross-section.

O método de MQO foi escolhido pois, caso todos os pressupostos do Modelo de Regressão Linear Clássico (MRLC) sejam válidos, o estimador calculado por esse método será o que possui menor variância quando comparado com outros estimadores lineares não viesados ou não tendenciosos ${ }^{5}$. Para aferir se os modelos propostos seguem as hipóteses do MRLC, foram feitos os seguintes testes: a) para averiguar a boa especificação dos modelos, foi realizado o teste RESET; b) o teste Jarque-Bera para normalidade dos resíduos; e c) o teste White foi feito nos modelos para verificação do pressuposto de homoscedasticidade ${ }^{6}$ (GREENE, 2012).

\footnotetext{
${ }^{5}$ Os pressupostos do MRLC são: i) linearidade dos parâmetros; ii) posto completo (as observações são linearmente independentes); iii) exogeneidade das variáveis independentes; e iv) homoscedasticidade e não autocorrelação dos resíduos. Embora a suposição de normalidade dos resíduos não seja necessária para a estimação, ela é útil para construção de intervalos de confiança e estatísticas de teste. Assim, foi analisada juntamente aos outros pressupostos (GREENE, 2012).

${ }^{6}$ Autocorrelação dos resíduos é uma violação dos pressupostos da regressão linear mais comum em estudos de séries temporais e dados em painel. Portanto, como a presente pesquisa trabalha com seis modelos cross section, os testes relativos à verificação desse problema não foram incluídos nos testes de diagnóstico (GREENE, 2012).
} 
Além dos testes realizados para verificar a confiabilidade dos modelos, três aspectos foram levados em conta. Primeiro a significância da regressão como um todo a partir do teste da estatística $\mathrm{F}$, depois a significância individual dos estimadores a partir da distribuição " $\mathrm{t}$ ” de Student, e, por fim, foi analisado o coeficiente de determinação ajustado ( $\mathrm{R}^{2}$ ajustado) para inquirir se o modelo proposto tem um nível de explicação satisfatório (GUJARATI; PORTER, 2011).

\section{Resultados e discussões}

Esta seção apresenta as estatísticas descritivas das variáveis utilizadas e os resultados da estimação do modelo, mostrando o impacto do tamanho e da conduta inovativa no desempenho das firmas analisadas. São apresentados e discutidos os resultados do modelo e dos testes para verificar a confiabilidade e significância do modelo. A Tabela 2 mostra um sumário das estatísticas descritivas das variáveis utilizadas:

Tabela 2 - Estatística descritiva das variáveis

\begin{tabular}{|c|c|c|c|c|c|}
\hline Ano & $\begin{array}{l}\text { Estatística } \\
\text { Descritiva }\end{array}$ & $\begin{array}{c}\text { RLV } \\
(\mathrm{R} \$ 1.000,00)\end{array}$ & $\begin{array}{c}\text { PO }\left(\mathbf{N}^{\circ} \text { de pessoas }\right. \\
\text { ocupadas) }\end{array}$ & $\begin{array}{c}\text { INOV } \\
(\mathrm{R} \$ 1.000,00)\end{array}$ & $\begin{array}{c}\text { PDI } \\
(\mathbf{R} \$ 1.000,00)\end{array}$ \\
\hline \multirow{9}{*}{2008} & Mínimo & 4372872 & 9100 & 92096 & 3136 \\
\hline & $1^{\circ}$ Quartil & 12983959 & 79025 & 454510 & 37971 \\
\hline & Mediana & 29601414 & 127079 & 912536 & 104192 \\
\hline & Média & 49898317 & 198175 & 1423779 & 400763 \\
\hline & $3^{\circ}$ Quartil & 57821517 & 246844 & 1690152 & 477543 \\
\hline & Máximo & 279282136 & 1308081 & 5823511 & 2914512 \\
\hline & Desvio Padrão & 5812738 & 224941,2 & 1503777 & 663466,3 \\
\hline & Curtose & 4,70 & 12,88 & 1,68 & 5,51 \\
\hline & Assimetria & 2,13 & 3,22 & 1,61 & 2,43 \\
\hline \multirow{9}{*}{2011} & Mínimo & 2617592 & 9626 & 76762 & 10191 \\
\hline & $1^{\circ}$ Quartil & 17077722 & 80948 & 588697 & 61634 \\
\hline & Mediana & 37853144 & 144659 & 1065491 & 223043 \\
\hline & Média & 62271141 & 221118 & 1609295 & 511159 \\
\hline & $3^{\circ}$ Quartil & 75326874 & 275708 & 1846475 & 660608 \\
\hline & Máximo & 386232882 & 1562665 & 7814361 & 2403501 \\
\hline & Desvio Padrão & 7499617 & 267377 & 1633920 & 698047,4 \\
\hline & Curtose & 6,99 & 13,92 & 3,9 & 2,1 \\
\hline & Assimetria & 2,44 & 3,37 & 1,94 & 1,8 \\
\hline
\end{tabular}


(continuação)

\begin{tabular}{|c|c|c|c|c|c|}
\hline Ano & $\begin{array}{l}\text { Estatística } \\
\text { Descritiva }\end{array}$ & $\begin{array}{c}\text { RLV } \\
(\mathbf{R} \$ \mathbf{1 . 0 0 0 , 0 0 )}\end{array}$ & $\begin{array}{c}\text { PO (No de pessoas } \\
\text { ocupadas) }\end{array}$ & $\begin{array}{c}\text { INOV } \\
(\mathrm{R} \$ \mathbf{1 . 0 0 0 , 0 0})\end{array}$ & $\begin{array}{c}\text { PDI } \\
(\mathrm{R} \$ 1.000,00) \\
\end{array}$ \\
\hline \multirow{9}{*}{2014} & Mínimo & 3758023 & 15988 & 106239 & 38378 \\
\hline & $1^{\circ}$ Quartil & 22698018 & 87912 & 543205 & 111232 \\
\hline & Mediana & 49699868 & 158542 & 1337620 & 287143 \\
\hline & Média & 77986407 & 229409 & 2092943 & 633988 \\
\hline & $3^{\circ}$ Quartil & 86114665 & 278163 & 2361680 & 865938 \\
\hline & Máximo & 525606581 & 1631159 & 14809133 & 3524329 \\
\hline & Desvio Padrão & 9835370 & 276182,3 & 2643559 & 7981382,2 \\
\hline & Curtose & 9,15 & 14,69 & 11,58 & 3,1 \\
\hline & Assimetria & 2,81 & 3,48 & 3,08 & 1,83 \\
\hline
\end{tabular}

Fonte: Elaborado pelos autores a partir dos dados da pesquisa.

Observando os dados da Tabela 2, elaborou-se a Tabela 3, que mostra os setores responsáveis pelo Mínimo e Máximo, além dos setores com comportamento mais próximo à média das observações.

Tabela 3 - Setores que representam o máximo, o mínimo e o comportamento mais próximo à média dos 38 selecionados

\begin{tabular}{|c|c|c|c|c|}
\hline Ano & Variável & Máximo & Mínimo & Média \\
\hline \multirow{4}{*}{2008} & RLV & \multirow{3}{*}{$\begin{array}{l}\text { Fabricação de } \\
\text { Produtos } \\
\text { Alimentícios }\end{array}$} & $\begin{array}{l}\text { Pesquisa e } \\
\text { Desenvolvimento }\end{array}$ & $\begin{array}{l}\text { Fabricação de } \\
\text { Produtos de Minerais } \\
\text { Não-Metálicos } \\
\end{array}$ \\
\hline & $\mathrm{PO}$ & & $\begin{array}{l}\text { Fabricação de Celulose e } \\
\text { Outras Pastas }\end{array}$ & Fabricação de Móveis \\
\hline & INOV & & $\begin{array}{l}\text { Fabricação de } \\
\text { componentes eletrônicos }\end{array}$ & \multirow{2}{*}{$\begin{array}{l}\text { Produtos } \\
\text { Farmoquímicos e } \\
\text { Farmacêuticos }\end{array}$} \\
\hline & PDI & $\begin{array}{l}\text { Pesquisa e } \\
\text { Desenvolvimento }\end{array}$ & $\begin{array}{l}\text { Fabricação de Coque e } \\
\text { Biocombustíveis }\end{array}$ & \\
\hline \multirow{4}{*}{2011} & RLV & \multirow{3}{*}{$\begin{array}{l}\text { Fabricação de } \\
\text { Produtos } \\
\text { Alimentícios }\end{array}$} & $\begin{array}{l}\text { Pesquisa e } \\
\text { Desenvolvimento }\end{array}$ & $\begin{array}{l}\text { Fabricação de } \\
\text { Máquinas Aparelhos } \\
\text { e Materiais Elétricos }\end{array}$ \\
\hline & $\mathrm{PO}$ & & \multirow[b]{2}{*}{$\begin{array}{l}\text { Fabricação de Celulose e } \\
\text { Outras Pastas }\end{array}$} & Fabricação de Móveis \\
\hline & INOV & & & $\begin{array}{l}\text { Metalurgia de Metais } \\
\text { Não-Ferrosos e } \\
\text { Fundição }\end{array}$ \\
\hline & PDI & Refino de Petróleo & $\begin{array}{l}\text { Impressão e Reprodução } \\
\text { de Gravações }\end{array}$ & $\begin{array}{l}\text { Fabricação de } \\
\text { Equipamentos de } \\
\text { Comunicação }\end{array}$ \\
\hline
\end{tabular}

(continua) 
(continuação)

\begin{tabular}{l|l|l|l|l}
\hline Ano & Variável & \multicolumn{1}{c|}{ Máximo } & \multicolumn{1}{c|}{ Mínimo } & \multicolumn{1}{c}{ Média } \\
\hline \multirow{2}{*}{$\mathbf{2 0 1 4}$} & RLV & $\begin{array}{l}\text { Fabricação de } \\
\text { Produtos } \\
\text { Alimentícios }\end{array}$ & $\begin{array}{l}\text { Fabricação de } \\
\text { componentes } \\
\text { eletrônicos }\end{array}$ & $\begin{array}{l}\text { Fabricação de Peças e } \\
\text { Acessórios para } \\
\text { Veículos }\end{array}$ \\
\cline { 2 - 5 } & PO & Indústrias Extrativas \\
\cline { 2 - 5 } & INOV & Telecomunicações & $\begin{array}{l}\text { Fabricação de Celulose } \\
\text { e Outras Pastas }\end{array}$ & $\begin{array}{l}\text { Fabricação de Artigos } \\
\text { de Borracha e } \\
\text { Plástico }\end{array}$ \\
\cline { 2 - 5 } & PDI & $\begin{array}{l}\text { Pesquisa e } \\
\text { Desenvolvimento }\end{array}$ & $\begin{array}{l}\text { Edição e Gravação de } \\
\text { Música }\end{array}$ & Indústrias Extrativas \\
\hline
\end{tabular}

Fonte: Elaborado pelos autores.

Analisando os máximos e mínimos da Tabela 3, nota-se uma sugestão de correlação positiva entre as variáveis para os três anos, pois o setor de Fabricação de Produtos Alimentícios apresentou a RLV máxima e a maior população ocupada e, em 2008 e 2011, esse mesmo setor também apresentou os maiores gastos totais com atividades inovativas. Já o setor de Pesquisa e Desenvolvimento apresentou os maiores gastos com atividades internas de pesquisa e desenvolvimento, resultado esperado dadas as atribuições desse setor ${ }^{7}$.

Já em relação aos mínimos, em 2011 o setor de Fabricação de Celulose e Outras Pastas apresentou a menor população ocupada e os menores gastos totais em atividade inovativas, e em 2008 esse setor já figurava como a menor PO e em 2014 continuou com a menor INOV. Em 2014, o setor de Fabricação de Componentes eletrônicos apresentou a menor RLV e a menor PO, sendo que em 2008 já havia apresentado os menores gastos totais com inovação. O setor de Pesquisa e Desenvolvimento aparece aqui, por dois anos seguidos, como a menor RLV. O baixo desempenho em receita do setor de Pesquisa e Desenvolvimento, concomitante aos grandes investimentos em atividades internas de P\&D, pode ser explicado pelas atribuições do setor, que não registra receita quando um produto é implementado no mercado e sim quando vende um produto inovador a um terceiro, que irá implementá-lo, ou quando publica artigos científicos com significativo grau de novidade.

\footnotetext{
${ }^{7}$ As empresas do setor de serviços ligados à Pesquisa e Desenvolvimento são aquelas que implementam a inovação de produto ou processo quando o produto é entregue ao cliente (sem haver necessidade de implementação efetiva no mercado), ou, no caso de empresas que promovem pesquisa básica, por meio da publicação de artigos com significativo grau de novidade científica e tecnológica (PINTEC, 2016).
} 
Os setores que aparecem com o comportamento mais próximo à média das variáveis são mais aleatórios, mas algum destaque cabe ao setor de Produção de Farmoquímicos e Farmacêuticos, que, em 2008, ficou mais próximo à média de INOV e PDI, e para as Indústrias Extrativas, que em 2014 ficaram na média de PO e PDI.

No que se refere às regressões estimadas por MQO, foram realizados os testes de diagnósticos já mencionados. Em geral o teste RESET mostrou uma boa especificação da maioria dos modelos e todos apresentaram resíduos com distribuição normal ${ }^{8}$. Como a presença de heteroscedasticidade foi detectada em algumas regressões, optou-se por estimar todos os modelos com correção de White, para dar robustez à inferência estatística. Vale ressaltar que a correção de White age no âmbito do erro padrão, não influenciando o teste da estatística $\mathrm{F}$ e os coeficientes de determinação e permitindo uma inferência estatística apropriada (GREENE, 2012). A Tabela 4 mostra o resultado das seis regressões já com a correção de White e com suas respectivas estatísticas F, " $t$ ” de Student, coeficiente de determinação e coeficiente de determinação ajustado.

Conforme exposto, os sinais de todos os coeficientes estão de acordo com a teoria econômica abordada. Além disso, a forma funcional Log-Log, ao fornecer as elasticidades, permite uma interpretação percentual dos coeficientes das variáveis dependentes.

Os resultados da Tabela 4 demonstram que as regressões como um todo são válidas a um nível de confiança de $95 \%$. A estatística $\mathrm{F}$ tabelada para os graus de liberdade dos modelos no nível de confiança proposto é inferior a 2,86 (GUJARATI; PORTER, 2011). Portanto, o F calculado é maior que o F tabelado, permitindo a rejeição de $\mathrm{H}_{0}$ do teste. A análise do valor $\mathrm{t}$, por sua vez, permite concluir que para os modelos de Tipo 2, em todos os anos, os coeficientes foram significativos ao nível de significância de $1 \%$. Já nos modelos de Tipo 1, o coeficiente de PO foi significativo em um nível de significância de $10 \%$ para todos os anos. Para todos os outros coeficientes do Tipo 1, os coeficientes foram significativos ao nível de significância de $1 \%$.

\footnotetext{
${ }^{8}$ Ao realizarem-se as regressões, notou-se, em todos os casos, uma grande anomalia nos resíduos provocada pela observação de número 38 (setor de Pesquisa e Desenvolvimento), que pode ter sido provocada pela grande disparidade entre os gastos com atividades internas de P\&D e a RLV. Assim, incluiu-se uma variável binária DUMMY para captar a distorção. Essa variável assume o valor 1 para a observação 38 e valor 0 , em caso contrário. Destarte, a normalidade dos resíduos em todas as regressões foi obtida com a inserção dessa variável.
} 
Tabela 4 - Regressões com correção de White

\begin{tabular}{|c|c|c|c|c|c|c|}
\hline Ano & Modelo & Variáveis & Estimador & $\begin{array}{l}\text { Desvio } \\
\text { Padrão }\end{array}$ & Valor $\mathbf{t}$ & $\operatorname{Pr}(>|\mathbf{t}|)$ \\
\hline \multirow{10}{*}{2008} & \multirow{5}{*}{ Tipo 1} & $C$ & $4,5131 * * *$ & 0,7346 & 6,1436 & 0,0000 \\
\hline & & $P O$ & $0,1338 *$ & 0,0749 & 1,7875 & 0,0828 \\
\hline & & $I N O V$ & $0,8193 * * *$ & 0,0733 & 11,1748 & 0,0000 \\
\hline & & \multicolumn{4}{|c|}{$\mathrm{R}^{2}: 0,8776 \quad \mathrm{R}^{2}$ ajustado: 0,8668} & \\
\hline & & \multicolumn{5}{|c|}{ Estatística F: 81,2846 em 3 e 34 Graus de Liberdade; valor-p: 0,0000 } \\
\hline & \multirow{5}{*}{ Tipo 2} & $C$ & $6,0459 * * *$ & 0,9942 & 6,0810 & 0,0000 \\
\hline & & $P O$ & $0,5278 * * *$ & 0,0804 & 6,5677 & 0,0000 \\
\hline & & $P D I$ & $0,4245 * * *$ & 0,0685 & 6,2010 & 0,0000 \\
\hline & & \multicolumn{4}{|c|}{$\mathrm{R}^{2}: 0,7684 \quad \mathrm{R}^{2}$ ajustado: } & \\
\hline & & \multicolumn{5}{|c|}{ Estatística F: 37,6218 em 3 e 34 Graus de Liberdade; valor-p: 0,0000 } \\
\hline \multirow{10}{*}{2011} & \multirow{5}{*}{ Tipo 1} & $C$ & $4,1115^{* *}$ & 1,6721 & 2,4589 & 0,0192 \\
\hline & & $P O$ & $0,2449 *$ & 0,1309 & 15 & 0,0699 \\
\hline & & INOV & $0,7543 * * *$ & 0,1087 & 6,9406 & 0,0000 \\
\hline & & \multicolumn{2}{|c|}{$\mathrm{R}^{2}: 0,8152$} & \multicolumn{3}{|c|}{$\mathrm{R}^{2}$ ajustado: 0,7989} \\
\hline & & \multicolumn{5}{|c|}{ Estatística F: 50,0141 em 3 e 32 Graus de Liberdade; valor-p: 0,0000 } \\
\hline & \multirow{5}{*}{ Tipo 2} & $C$ & $6,0267 * * *$ & 1,2829 & 4,6976 & 0,0000 \\
\hline & & $P O$ & $0,5150 * * *$ & 0,1030 & 78 & 0,0000 \\
\hline & & $P D I$ & $0,4363 * * *$ & 0,0661 & 6,6054 & 0,0000 \\
\hline & & $\mathrm{R}^{2}: 0,8130$ & & $\mathrm{R}^{2}$ ajustado: & 966 & \\
\hline & & \multicolumn{5}{|c|}{ Estatística F: 49,2966 em 3 e 34 Graus de Liberdade; valor-p: 0,0000 } \\
\hline \multirow{10}{*}{2014} & \multirow{5}{*}{ Tipo 1} & $C$ & $5,4725 * * *$ & 1,5129 & 3,6172 & 0,0010 \\
\hline & & $P O$ & $0,2190 *$ & 0,1236 & 1,7717 & 0,0854 \\
\hline & & $I N O V$ & $0,6875 * * *$ & 0,1261 & 5,4530 & 0,0000 \\
\hline & & \multicolumn{5}{|c|}{$\mathrm{R}^{2}: 0,8057 \quad \mathrm{R}^{2}$ ajustado: 0,7886} \\
\hline & & \multicolumn{5}{|c|}{ Estatística F: 47,0091 em 3 e 34 Graus de Liberdade; valor-p: 0,0000 } \\
\hline & \multirow{5}{*}{ Tipo 2} & $C$ & $6,0015 * * *$ & 1,4860 & 4,0388 & 0,0003 \\
\hline & & $P O$ & $0,5259 * * *$ & 0,1204 & 4,3696 & 0,0001 \\
\hline & & $P D I$ & $0,4316 * * *$ & 0,0943 & 4,5774 & 0,0001 \\
\hline & & \multirow{2}{*}{\multicolumn{2}{|c|}{$\begin{array}{l}\mathrm{R}^{2}: 0,7326 \\
\text { Estatística } \mathrm{F}\end{array}$}} & \multicolumn{3}{|c|}{$\mathrm{R}^{2}$ ajustado: 0,7090} \\
\hline & & & & m 3 e $34 \mathrm{C}$ & Liberd & val \\
\hline
\end{tabular}

Nota: *** significativo à $1 \% ; * *$ significativo à $5 \% ; *$ significativo à $10 \%$.

Fonte: Elaborado pelos autores a partir dos dados da pesquisa.

A análise do $\mathrm{R}^{2}$ ajustado mostra que nenhum dos modelos explica menos que $70 \%$ das variações da RLV, um valor satisfatório, dada a complexidade econômica da realidade de uma firma, e por se tratar de dados cross-section. Para os modelos Tipo 1, em média, $81,81 \%$ das variações na RLV puderam ser explicadas pela variação da População Ocupada e dos Gastos Totais com Atividades Inovativas. Já para os modelos Tipo $2,75,12 \%$ das variações na RLV 
puderam ser explicadas, em média, pelas variações da População Ocupada e dos Dispêndios com Atividades Internas de P\&D.

O Gráfico 1 mostra o comportamento da influência das variáveis PO e INOV sobre a RLV, nos modelos do Tipo 1 (efeitos marginais da Tabela 4), para os anos de 2008, 2011 e 2014. Verifica-se que a influência da variável PO foi crescente entre 2008 e 2011, depois apresentando uma leve queda entre 2011 e 2014. Uma variação de $1 \%$ na População Ocupada corresponderia a uma variação de aproximadamente 0,13\% na RLV em 2008, e 0,24\%, em 2011 (caindo para $0,21 \%$ em 2014). Por sua vez, INOV apresentou um impacto decrescente ao longo de todos os anos estudados. Se em 2008 apresentou uma influência de quase $0,82 \%$ sobre a RLV, em 2014 uma variação de 1\% em INOV correspondeu a uma variação de 0,68\% sobre a RLV. De Negri e Cavalcante (2013) apontam algumas possíveis causas para essa queda do efeito marginal de INOV sobre a RLV: externamente cabe ressaltar os reflexos da crise internacional de 2008-2009, e, internamente, o aprofundamento da especialização produtiva brasileira baseada em setores de baixa intensidade tecnológica e o pequeno número de empresas de capital nacional nos setores intensivos em conhecimento e tecnologia.

\section{Gráfico 1 - Impacto de PO e INOV sobre RLV, nos modelos do Tipo 1 (2008-2014)}

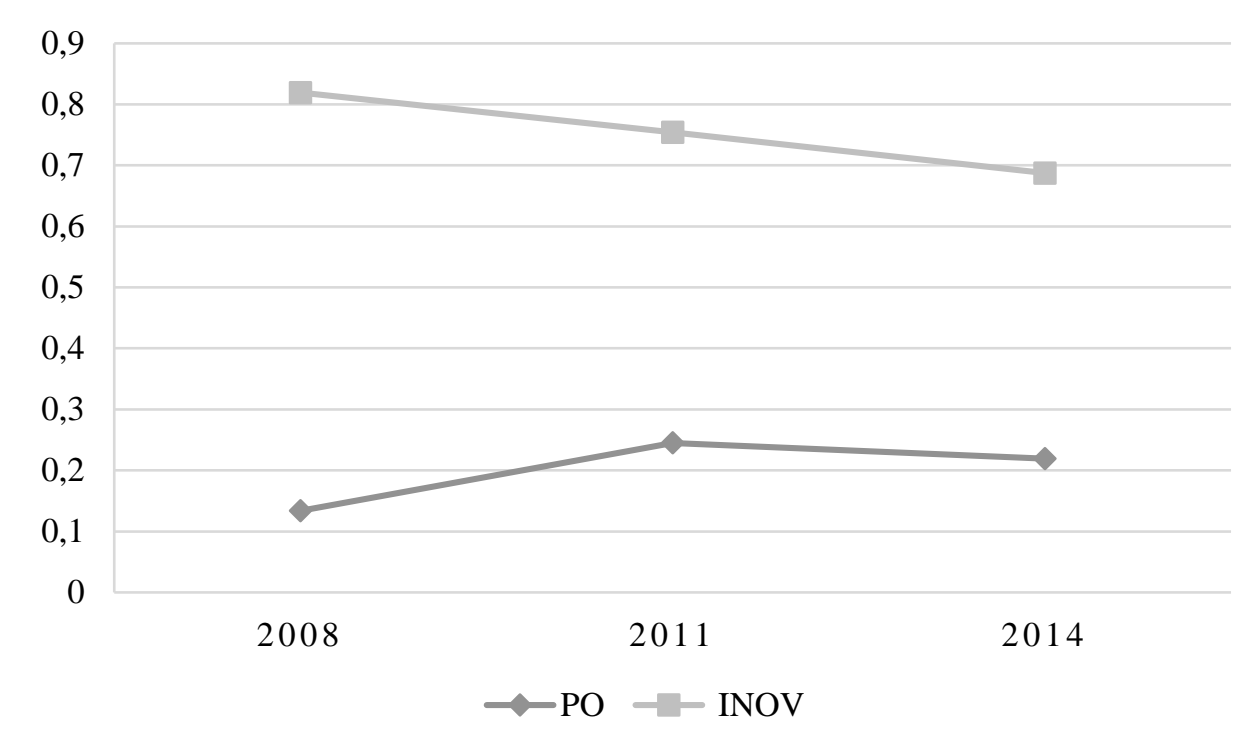

Fonte: Elaborado pelos autores a partir dos dados da pesquisa. 
O Gráfico 2 mostra a influência, em 2008, 2011 e 2014, das variáveis PO e PDI sobre o comportamento da RLV, nos modelos de Tipo 2 (efeitos marginais da Tabela 4). Observa-se que, para os modelos Tipo 2, a População Ocupada representa um impacto maior que nos modelos Tipo 1 e aproximadamente constante para os anos selecionados: uma variação de $1 \%$ em PO correspondeu a uma variação média de $0,52 \%$ da RLV. A variável PDI mostrou-se menos impactante que INOV, o que pode ser explicado, pois PDI é um dos componentes que formam INOV. Além disso, diferentemente de INOV, apresentou um comportamento quase constante, mas é possível notar um leve crescimento: em uma média para os três anos, uma variação de $1 \%$ em PDI representou uma variação de aproximadamente $0,43 \%$ na RLV.

\section{Gráfico 2 - Impacto de PO e PDI sobre RLV, nos modelos de Tipo 2 (2008-2014)}

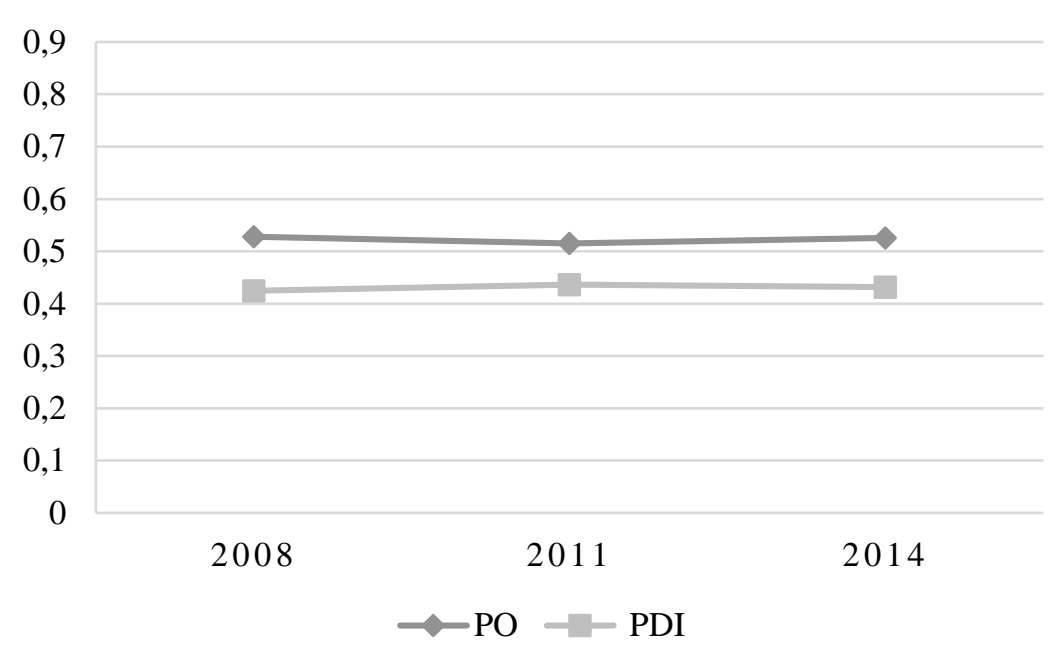

Fonte: Elaborado pelos a partir dos dados da pesquisa.

Assim como concluído por Becker e Dal Bosco (2011) e Silva e Santana (2015), pode-se notar a importância do tamanho e dos gastos com inovação no faturamento das empresas, mostrando a consistência histórica dos impactos positivos. Ainda que a tendência do coeficiente de INOV tenha sido levemente decrescente nos anos analisados, os investimentos em inovação mostram-se rentáveis às empresas, tornando a rotina inovativa um alvo a ser alcançado pelas firmas. Por fim, além das análises em pesquisas anteriores, os gastos com atividades internas de $\mathrm{P} \& \mathrm{D}$ apareceram como uma importante variável para o faturamento das empresas. Se levarmos em consideração que, em 2014, INOV 
apresentou um impacto de, aproximadamente, 0,69\% e PDI de 0,43\%, pode-se notar que, no último ano verificado, a maior parte do impacto das atividades inovativas deveu-se aos gastos com atividades internas de P\&D.

De toda a discussão precedente, pode-se finalmente concluir que a adoção dos investimentos em atividades inovativas representa, à luz da teoria evolucionária Neoschumpeteriana, o estabelecimento de uma rotina. Essa rotina, por sua vez, passa pelo processo de busca e seleção gerado pelas inter-relações entre mercado e firma. Os resultados positivos, tanto de INOV quanto de PDI, mostram que tal estratégia não só é positiva sobre desempenho da firma, como, quando transformada em rotina, revela-se bem-sucedida em termos evolucionários, sendo sancionada pelos mecanismos de busca e seleção ao longo do tempo.

\section{Considerações finais}

Como visto ao longo do artigo, a teoria evolucionária da firma coloca a estratégia de inovação no centro do desenvolvimento econômico. A capacidade de inovar, de destruir antigos paradigmas produtivos para alcançar novas capacidades, e fazê-lo continuamente, é marca do avanço econômico nos diversos setores da economia.

O estudo proposto avançou na literatura ao incluir a PINTEC de 2016 e ao analisar, além da indústria de transformação, a indústria extrativa e o setor de serviços ligados à tecnologia, comprovando que a inovação de produtos e processos é importante para os mercados de uma forma geral. Também pode ser considerado outro avanço importante a divisão do esforço e inovação em duas partes: o impacto total dos dispêndios com atividades inovadoras sobre a receita líquida de vendas, e a verificação particular da influência dos gastos com atividades internas de $\mathrm{P} \& \mathrm{D}$ sobre tal receita.

A teoria econômica, ratificada pelos modelos estimados, mostra que o tamanho do setor e a estratégia (conduta) inovadora têm uma influência positiva sobre as vendas e, consequentemente, para o crescimento das empresas dos diversos setores. Contudo, por meio de uma comparação histórica, observou-se que, no Brasil, mesmo que a influência da inovação seja positiva, ela decresceu entre os anos de 2008 e 2014. Isso não significa que os dispêndios em si tenham diminuído, pois entre 2008 e 2014 os gastos totais com inovação apresentaram 
uma taxa de crescimento média de $57,3 \%$ e os gastos com atividades internas de P\&D apresentaram uma taxa de crescimento média de $208,59 \%$.

Assim, o aumento dos dispêndios com concomitante decrescimento da relevância sobre as vendas pode ser explicado pelos elevados custos em se criar, manter e ampliar um setor de P\&D, cada vez mais tecnológico, nas firmas. Também contribuem para esse decrescimento as incertezas que envolvem a atividade inovadora (exacerbadas no referido período, que inclui a grande crise financeira global de 2008 e o desestímulo aos investimentos empresariais já claros durante o primeiro governo Dilma no Brasil) e os custos para a efetiva implementação de uma inovação no mercado (que podem ser caracterizados como sunk costs).

A pesquisa encontrou algumas limitações quanto aos dados da PINTEC, pois, com o intuito de estudar o comportamento das variáveis por três anos diferentes, as únicas que puderam ser consideradas sobre inovação foram os gastos totais com inovação e os gastos com atividades internas de P\&D. Assim, sugerese que, em pesquisas posteriores, sejam feitas abordagens mais detalhadas mediante acesso a mais tipos de dados sobre inovação dos triênios seguintes da referida pesquisa.

Por fỉm, à guisa de conclusão, pode-se dizer que o trabalho atingiu o resultado esperado, ampliando o alcance da análise encontrada em trabalhos anteriores e ratificando as explicações da teoria econômica Neoschumpeteriana, inclusive com um grau satisfatório de robustez nos modelos elaborados.

\section{Referências}

AZEVEDO, P. F. Organização Industrial. In: PINHO, D. B.; VASCONCELLOS, M. A. S. (Org.). Manual de Economia. São Paulo: Saraiva, 1998.

BAUMOL, W. The Entrepreneur in Economic Theory. In: BAUMOL, W. (Org.). Entrepreneurship, Managements and the Structure of Payoffs. Massachusets: MIT Press, p. 1-17, 1993.

BECKER, M. M.; DAL BOSCO, M. R. A importância do investimento em inovações e a dimensão da estrutura produtiva das empresas para o seu desempenho: uma análise da indústria de transformação brasileira. V Encontro de Economia Catarinense, Florianópolis, 2011. 
CÁRIO, S. A. F. Contribuição do paradigma microdinâmico neo-schumpeteriano à teoria econômica contemporânea. Textos de Economia, v. 6, n. 1, p. 155-170, 1995.

CÁRIO, S. A. F.; PEREIRA, C. B. Inovação e desenvolvimento capitalista: referências histórica e conceitual de Schumpeter e dos neo-Schumpeterianos para uma teoria econômica dinâmica. XXX Encontro Nacional de Economia Política, Florianópolis, 2002.

CAVALCANTE, L. R.; DE NEGRI, F. Trajetória Recente dos indicadores de inovação no Brasil. Texto para discussão 1659. Brasília: Ipea, 2011. Disponível em: http://www.ipea.gov.br/portal/images/stories/PDFs/TDs/td_1659.pdf. Acesso em: 01 nov. 2019.

DE NEGRI, F.; CAVALCANTE, L. R. Análise dos dados da PINTEC 2011. Nota Técnica 15. Rio de Janeiro: Ipea, 2013. Disponível em: http://repositorio. ipea.gov.br/bitstream/11058/5978/1/NT_n15_analise.pdf. Acesso em: 18 abr. 2019.

GREENE, W. H. Econometric Analysis. Nova York: Prentice Hall, 2012.

GUJARATI, D. N.; PORTER, D. C. Econometria Básica. Porto Alegre: AMGH, 2011.

HASENCLEVER, L.; TORRES, R. O Modelo Estrutura, Conduta e Desempenho e seus Desdobramentos. In: KUPFER, D.; HASENCLEVER, L. (Org.). Economia Industrial. 2. ed. Rio de Janeiro: Elsevier, p. 41-51. 2013.

HERSCOVICI, A. Technical progress, economic growth and deindustrialization: the limits of the kaldorian logic. XII Annual Encounter of the Association of Heterodox Economy, Manchester, 2010.

JENSEN, J.; MENEZES-FILHO, N.; SBRAGIA, R. Os determinantes dos gastos em P\&D no Brasil: uma análise com dados em painel. Estudos Econômicos, v. 34, n. 4, p. 661-691, 2004.

KANNEBLEY JR, S.; PORTO, G. S.; PAZELLO, E. T. Inovação na Indústria Brasileira: uma Análise Exploratória a Partir da PINTEC. Revista Brasileira de Inovação, v. 3, n. 1, p. 87. 2004. Disponível em: https://periodicos.sbu.unicamp.br /ojs/index.php/rbi/article/view/8648893. Acesso em: 20/03/2019.

KUPFER, D. Padrões de concorrência e competitividade. ENCONTRO NACIONAL DE ECONOMIA, Campos do Jordão, 1992.

LASTRES, H. M.; CASSIOLATO, J. E. Novas políticas na era do conhecimento: o foco em arranjos produtivos e inovativos locais. Parcerias estratégicas, v. 8, n. 17, p. 5-30, 2003. 
LOPES, H. C. O modelo Estrutura-Conduta-Desempenho e a Teoria Evolucionária Neoschumpeteriana: uma proposta de integração teórica. Revista de Economia Contemporânea, v. 20, n. 2, p. 336-358, ago. 2016. Disponível em: http://www. ie.ufrj.br/images/blog/06_REC_20.2_O-modelo-ECD-e-a-teoria-evolucionaria.pdf Acesso em: 30/10/2019.

MACEDO, P. B.; ALBUQUERQUE, E. M. P\&D e tamanho da empresa: evidência empírica sobre a indústria brasileira. Textos Para Discussão, 117 CEDEPLAR/UFMG. Belo Horizonte, 1997.

MENDONÇA, E. C.; LIMA, M. A. Estrutura de mercado e desempenho na indústria de transformação brasileira: uma análise utilizando medida diretas de eficiência. Eventos Realizados IPEA, Rio de Janeiro, 2009. Disponível em: http://www.ie.ufrj.br/datacenterie/pdfs/seminarios/pesquisa/texto2804.pdf. Acesso em: 16/04/2019.

NELSON, R. R.; WINTER, S. G. An Evolutionary Theory of Economic Change. Cambridge: Harvard University Press, 1982.

PINTEC. Pesquisa de Inovação 2014. Rio de Janeiro, 2016. Disponível em: https://biblioteca.ibge.gov.br/visualizacao/livros/liv99007.pdf. Acesso em: 20/03/2019.

POSSAS, M. L. Eficiência Seletiva: uma perspectiva neo-schumpeteriana sobre questões econômicas normativas. Revista de Economia Política, v. 24, n. 1, p. 74-95, jan. 2004. Disponível em: https://www.researchgate.net/publication/255649 128_Eficiencia_Seletiva_uma_perspectiva_Neo-Schumpeteriana_evolucionaria_ sobre_questoes_economicas_normativas. Acesso em: 20/03/2019.

PÓVOA, L. M. C.; MONSUETO, S. E. Tamanho das Empresas, Interação com Universidades e Inovação. Revista de Economia, v. 37, n. 4, p. 9-24, 31 dez. 2011. Disponível em: http://revistas.ufpr.br/economia/article/view/28870. Acesso em: 18/03/2019.

ROBINSON, J. Novas contribuições à economia moderna. São Paulo: Vértice, 1988.

SCHERER, F. M.; ROSS, D. Industrial market structure and economic performance. Massachusetts: Houghton Mifflin Company, 1990.

SCHUMPETER, J. A. Capitalismo, Socialismo e Democracia. Rio de Janeiro: Fundo de Cultura, 1961. 
SCHUMPETER, J. A. Teoria do Desenvolvimento Econômico: uma investigação sobre lucros, capital, crédito, juro e o ciclo econômico. São Paulo: Nova Cultural, 1997.

SILVA, L. C.; SANTANA, J. R. de. Influência da inovação e do tamanho sobre o desempenho de empresas industriais: uma análise para o Brasil e regiões. Revista Econômica do Nordeste, v. 46, n. 3, p. 9-25, 2015.

TIRONI, L. F.; CRUZ, B. O. Inovação Incremental ou Radical: Há motivos para diferenciar? Uma abordagem com dados da PINTEC. Texto para discussão, 1360. Rio de Janeiro: IPEA, 2008.

VIEIRA, R. M. Teoria da firma e inovação: um enfoque neo-schumpeteriano. Cadernos de Economia, v. 14, n. 27, p. 36-49, 2010.

VIOTTI, E. B.; BAESSA, A. R.; KOELLER, P. Perfil da inovação na indústria brasileira: uma comparação internacional. In: DE NEGRI, J. A.; SALERNO, M. S. (Orgs.). Inovações, padrões tecnológicos e desempenho das firmas industriais brasileiras. Brasília: IPEA, 2009. 


\section{Apêndice A - Setores selecionados da PINTEC para os anos de 2008, 2011 e 2014}

\begin{tabular}{|c|c|}
\hline $\mathbf{N}^{\mathbf{0}}$ & Setor da Indústria ou Serviços \\
\hline 1 & Indústrias extrativas \\
\hline 2 & Fabricação de produtos alimentícios \\
\hline 3 & Fabricação de bebidas \\
\hline 4 & Fabricação de produtos do fumo \\
\hline 5 & Fabricação de produtos têxteis \\
\hline 6 & Confecção de artigos do vestuário e acessórios \\
\hline 7 & Preparação de couros e fabricação de artefatos de couro, artigos de viagem e calçados \\
\hline 8 & Fabricação de produtos de madeira \\
\hline 9 & Fabricação de celulose e outras pastas \\
\hline 10 & Fabricação de papel, embalagens e artefatos de papel \\
\hline 11 & Impressão e reprodução de gravações \\
\hline 12 & Fabricação de coque e biocombustíveis (álcool e outros) \\
\hline 13 & Refino de petróleo \\
\hline 14 & Fabricação de produtos químicos \\
\hline 15 & Fabricação de produtos farmoquímicos e farmacêuticos \\
\hline 16 & Fabricação de artigos de borracha e plástico \\
\hline 17 & Fabricação de produtos de minerais não-metálicos \\
\hline 18 & Produtos siderúrgicos \\
\hline 19 & Metalurgia de metais não-ferrosos e fundição \\
\hline 20 & Fabricação de produtos de metal \\
\hline 21 & Fabricação de componentes eletrônicos \\
\hline 22 & Fabricação de equipamentos de informática e periféricos \\
\hline 23 & Fabricação de equipamentos de comunicação \\
\hline 24 & Fabricação de outros produtos eletrônicos e ópticos \\
\hline 25 & Fabricação de máquinas, aparelhos e materiais elétricos \\
\hline 26 & Fabricação de máquinas e equipamentos \\
\hline 27 & Fabricação de automóveis, caminhonetas e utilitários, caminhões e ônibus \\
\hline 28 & Fabricação de cabines, carrocerias, reboques e recondicionamento de motores \\
\hline 29 & Fabricação de peças e acessórios para veículos \\
\hline 30 & Fabricação de outros equipamentos de transporte \\
\hline 31 & Fabricação de móveis \\
\hline 32 & Fabricação de produtos diversos \\
\hline 33 & Manutenção, reparação e instalação de máquinas e equipamentos \\
\hline 34 & Edição e gravação e edição de música \\
\hline 35 & Telecomunicações \\
\hline 36 & Atividades dos serviços de tecnologia da informação \\
\hline 37 & Tratamento de dados, hospedagem na internet e outras atividades relacionadas \\
\hline 38 & Pesquisa e desenvolvimento \\
\hline
\end{tabular}

Fonte: Elaborado pelos autores. 